Advances in

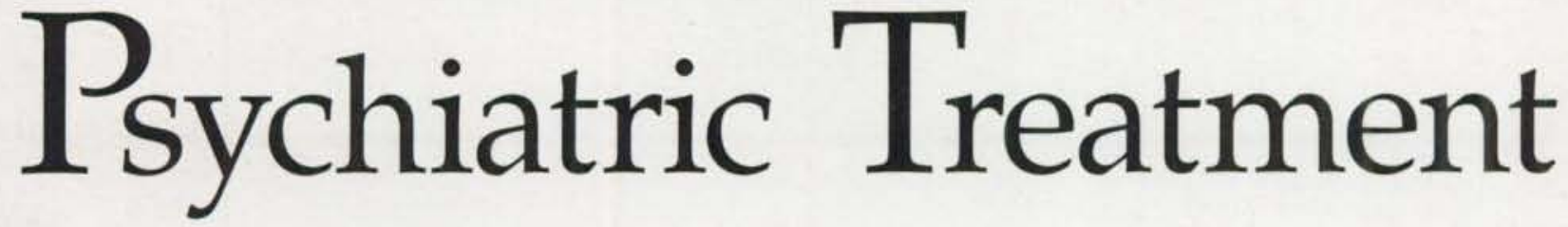

Wo Journal of Continuing Professional Development

\title{
The Royal College of Psychiatrists
}

Contents

Editorial: $A P T$ and standards for clinical practice. A. Sims

Training in psychiatry in Europe. F. Caldicott

Setting up an assertive community treatment service.

A. Kent \& T. Burns

Commentary. S. R. Hirsch

Neuroleptic malignant syndrome. D. Kohen $\mathcal{E}$ M. Bristow

Management aspects of care for the homeless mentally ill.

P. Timms

Consultants and leadership. J. Reed \& P. Hill

Case history: psychiatric management of adult autism.

G. O'Brien

Commentary. G. Holt

176

Managing depression in older people. C. Katona

\section{Editor Andrew Sims}

Editorial board Alistair Burns, Patricia Casey, John Cookson, David Cottrell, Nigel Eastman, Sheila Hollins, Jeremy Holmes, Alan Lee, Roy McClelland, Robin McCreadie, David Owens, Jan Scott, Greg Wilkinson 